\title{
Clarification of Research Study: ADHD Does Not Provide Special Conditions for Entrepreneurship
}

\author{
Hans-Olle Frummerin ${ }^{1}$ and Stefan Lindstrom ${ }^{2 *}$ \\ ${ }^{1}$ Management Consultant and Licensed Psychologist, Sweden \\ ${ }^{2}$ Management Consultant and Entreprenologist, Stockholm County, Sweden \\ *Corresponding author: MBA. Stefan Lindstrom, Management Consultant and Entreprenologist, Stockholm County, Sweden; E-mail: stefan@stefanlindstrom.com
}

Received: March 17, 2021; Accepted: March 22, 2021; Published: March 25, 2021

Is it the case that our hopes and wishful thinking about the state of affairs lead us to lose our analytical gaze and shortcomings in analysis?

In the article on $\mathrm{ADHD}$ and entrepreneurship that was published in The Journal of Applied Psychiatry, [1] the authors Frummerin and Lindström [2] emphasized that ADHD would not offer any special conditions for entrepreneurship and were critical of some article authors who emphasized that ADHD would provide favorable conditions for entrepreneurship.

To avoid a discussion characterized by seeing things in black and white, the article tried to describe the limitations that ADHD entails in a nuanced way with an insight that in exceptional cases there are designated ADHDs that could function entrepreneurially if there was support for them in other ways.

I.e., the article brought up:

"ADHD linked to restlessness and difficulty paying attention."

"ADHD. Difficulties in concentration and not being able to focus on performing tasks for a long period of time"

"A person with ADHD is often exposed to a significant challenge in enduring and reaching all the way until the task is completed".

It is interesting to note that some of those who read the article appreciated it because they perceived it as that ADHD can be an asset in entrepreneurial work. We the authors become self-critical and thoughtful about how we have expressed ourselves and how the readers have drawn conclusions from the article. In what way can we interpret these, albeit minority, reactions that for us are not in line with the message we hoped to convey?

There are certainly a variety of reasons why several readers of the article have not embraced the article's message about the limitations associated with ADHD.

To note is that is that several entrepreneurs or self-employed people with their own ADHD diagnoses who have claimed that they have read it, mention they perceived the article directly positive and ADHD as an asset, this which in itself is interesting due to the examples above mentioned, as well mentioned in the article about mental health and challenges in functioning in everyday life.
We cannot interpret this in any other way than that some debaters and trendsetters for several years have tried to convey that ADHD would provide conditions for entrepreneurial action without drawing attention to the limitations and problems that ADHD can bring to individuals in terms of mental health and challenges in functioning in everyday life.

In Sweden there has been a strong effort to find opportunities for everyone, and this is an extremely positive desire. Every individual should be able to have the opportunity to realize their full potential. But when it comes to giving ADHD diagnosed individuals extra ordinary hope to act as entrepreneurs, it may approach the unrealistic and possibly raise more hopes than realistic possibilities.

In the quest to find new types and varieties of management, and looking for new ways to lead where creativity and focus could add new qualities and energy for entrepreneurship. Which is fully understandable but also possibly contains more visionary approaches than being realistic. Entrepreneurship if it is to have a long-term viability often includes more trivial components such as stability and organizational ability.

It is interesting to note that the message we tried to convey did not reach everyone and because of that we feel compelled to supplement our argumentation. We have some comments.

Is it the case that the discussion that has taken place, not only in Sweden, has not taken into account that ADHD often affects and limits an individual's opportunities to function in an optimal way. In some articles, ADHD has been highlighted in such a way that one gets the impression that ADHD would provide special conditions to be an entrepreneur. What is the background to this?

Is it about wishful thinking and perceptual defense mechanisms?

That one has a picture and wishful thinking that it relates in a certain way. Or one does not have the patience and composure to read a text and analyse and draw conclusions.

Another factor that may possibly explain why one so reluctantly claims ADHD as a positive factor in this context is the image one makes of the entrepreneur. It is an image of an entrepreneur who leads an uncomplicated and clear business. 
Certainly, ADHD characterized have often been able to lead activities of this nature.

Having that said, it can be easily confused or even mixed together what is entrepreneurship, and what is entrepreneurship. Or what is self-employed and running its own business versus- what is entrepreneurship? [1,5].

A 2020 survey shows, [3] among other things, that the traditional image of the entrepreneur is no longer really adequate. Often one has had a simpler picture of entrepreneurs.

We can therefore not avoid stating that there has been and still is a general picture of the entrepreneur that can lead to mistakes with quick conclusions within the area.

We would like to emphasize that it is extremely commendable that we jointly try to create as favourable conditions as possible for individuals with ADHD behaviours. A variety of measures are needed at different levels that can make it easier for individuals with ADHD to develop their potential.

In the current debate no higher attention has been paid to the facts that say that ADHD often limits an individual's opportunities to function in an optimal way.
This can lead to the creation of a notion that ADHD would provide conditions that are not fulfilled in reality. As a consequence, this could mean that individuals with ADHD are expected to perform commitments that they do not in fact have the conditions to perform. The consequence could be that people with ADHD would end up in professional roles in which they feel great frustration or that they simply fail.

As we judge it based on the response to the article, [1] the opportunity thinking about ADHD that has developed over time has led to a wishful thinking that overlooks realities regarding professional roles and interactions in the workplace [4].

This requires a more analytical approach without wishful thinking and defense mechanisms. It benefits those with diagnosed ADHD the best.

\section{References}

1. Do Typical ADHD Traits Offer Advantages to Entrepreneurs? (sciaeon.org).

2. About us - Entrepreneur profile test.

3. New research about the entrepreneur in Sweden/Ny bild av den svenske entreprenören, (researchgate.net)

4. Do Typical ADHD Traits Offer Advantages to Entrepreneurs? (researchgate.net).

5. About the test - Entrepreneur profile test.

\section{Citation:}

Frummerin H-O, Lindstrom S (2021 Clarification of Research Study: ADHD Does Not Provide Special Conditions for Entrepreneurship. Ageing Sci Ment Health Stud Volume 5(1): 1-2. 